\title{
Effects of age at first access to range area on pecking behaviour and plumage quality of free-range layer chickens
}

\author{
M. Petek, E. Topal, and E. Cavusoglu \\ Department of Zootechnics, Faculty of Veterinary Medicine, University of Uludag, Bursa, Turkey \\ Correspondence to: M. Petek (petek@uludag.edu.tr)
}

Received: 14 July 2014 - Accepted: 12 January 2015 - Published: 9 March 2015

\begin{abstract}
The aim of this study was to investigate the effects of age on pecking behaviour and plumage quality of free-range laying hens during first access to range. Six hundred 16-week-old layer pullets obtained from a commercial company were housed in a experimental free-range house. The experimental house consisted of a slat-and-litter floor with range area and was divided into three similar pens. The pullets were randomly assigned to a control and two experimental groups according to age at first access to range area. The birds were allowed into the range area for the first time at 18,20 and 22 weeks of age in the groups of treatment I, treatment II and control, respectively. Pecking behaviour and plumage quality of the birds were measured for 8-week intervals from 24 to 48 weeks of age. Total feather damage significantly increased with age in all groups $(P<0.040$, $P<0.006, P<0.001)$. Compared to the control group, birds allowed into the range area earlier had less feather damage. The feather score of the tail body region in all groups was significantly greater (more damage) than in the others $(P<0.001)$. There were no significant differences for the total pecking behaviour of the birds in the groups at $24,32,40$ and 48 weeks of age. Incidents of gentle feather pecking in every period were more frequent, while aggressive pecking was less frequent $(P<0.026, P<0.007, P<0.001)$. It can be said that access to range area as early as possible at the beginning of the laying period may be useful to reduce the negative effect of feather pecking in free-range layer chickens.
\end{abstract}

\section{Introduction}

Injurious pecking is a common term used to describe feather pecking, vent pecking, cannibalism and toe pecking in laying hens. It is also a serious welfare concern because the pullingout of feathers causes pain, stress, injuries and increased susceptibility to disease (Petek and McKinstry, 2010). Injurious feather pecking can represent a big problem in all housing systems, even in free-range housing systems, with both economic implications for farmers and welfare implications for birds (Tauson et al., 2005; Sherwin et al., 2010, 2013).

Beak trimming and dim lighting are still the most effective husbandry practice used by the poultry industry and have long been employed to help reduce the deleterious effects of feather pecking and subsequent cannibalism (Petek and McKinstry, 2010). However, these are under criticism in terms of the welfare point of view (Brunberg et al., 2011).
Some countries have banned the hot-blade technique, which is most common technique for beak trimming. A general ban on the use of all techniques, including infrared, for beak trimming is expected by 2018 in several EU countries (Anonymous, 2013). In recent years, there has been increasing focus on alternative methods to reduce injurious pecking in laying hens. Some scientific evidence suggests that feather pecking and cannibalism could be largely prevented by the use of appropriate husbandry techniques without the use of beak trimming (Savory, 1995; Morris, 2007; Picket, 2008; Petek, 2013). There have been some on-farm studies on pecking and the welfare of laying hens in the literature (Nicol et al., 2003; Sherwin et al., 2010, 2013; Gilani et al., 2013). Recently, a set of husbandry advisory tools was developed to reduce injurious pecking in free-range layer chickens in the UK (Weeks et al., 2011; Lambton et al., 2013). 
It is clear that the risk of feather pecking in free-range layer chickens might be lower when an outdoor grazing area is provided. Mahboup et al. (2004) reported that the percentage of time spent on grassland and feather damage were inversely correlated. Lambton et al. (2010) showed that there was a detrimental effect of allowing range access before onset of laying and the risk of vent pecking might also be reduced by delaying the onset of laying and subsequently encouraging range use. A recent study also tested the effect of range access during rearing on feather pecking and ranging behaviour. That study found no effect of age of first range access on the amount of feather pecking (Gilani et al., 2014). In general, the conventional timing of first access to range area for free-range layer chickens is 22 or 24 age of weeks because of the period of adaptation of pullets to nest boxes and other housing environments. However there is a major concern about this period, because it may lead to an increase in feather pecking and cannibalism in layer chickens. This study was carried out to investigate the effects of age at first range access on pecking behaviour and plumage quality of free-range layer chickens.

\section{Material and methods}

Research was performed at the Research and Experimental Farm of Uludag University in Bursa, Turkey, and experimental procedures were employed in accordance with the principles and guidelines set out by the Committee of Uludag University on animal care. Six hundred 16-week-old Lohman Brown layer pullets obtained from a commercial company were reared in an experimental free-range house. At the beginning of the experiment, pullets were randomly distributed into three groups of 200 birds (control and two experimental groups) according to age at first range access.

\subsection{Management}

The indoor and outdoor (range) areas of the experimental house were divided into three similar pens $(6 \times 6 \mathrm{~m})$. The indoor part of each pen consisted of litter (one-third of floor space) and a slatted floor (white plastic slats, $100 \times 60 \mathrm{~cm}$ ). A rice hull layer of about $10 \mathrm{~cm}$ was used as a litter material. Birds in all groups were allocated equal space for feeders, drinkers and nest boxes. Automatic nest boxes (group nests; $1 \mathrm{~m}^{2}$ of nest space for every 100 hens), hanging feeders (each $30 \mathrm{~cm}$ in diameter with $10-15 \mathrm{~kg}$ capacity) and bell drinkers were provided for the birds in all groups. All birds were beak trimmed by method of hot blade (at first week of age) and mean stocking density within the groups was 6 birds per $1 \mathrm{~m}^{-2}$ indoor and 5 birds per $10 \mathrm{~m}^{-2}$ outdoors.

Birds in all groups were fed with a pullet grower diet containing $2850 \mathrm{kcal} \mathrm{kg}^{-1}$ metabolizable energy and $15 \%$ crude protein until 20 weeks of age. The standard layer diet was supplied (2700 $\mathrm{kcal} \mathrm{kg}^{-1}$ metabolizable energy and
$18 \%$ crude protein) between weeks 21 and 48 (NRC, 1994). Water and feed were provided ad libitum.

The birds were allowed into the range area for the first time at 18, 20 and 22 weeks of age in the groups of experiment I, experiment II and control, respectively. The groups were physically and visually separated from each other so that the birds in the 18 weeks of treatment did not affect the behaviour of the birds in the other treatments. During the experimental period, birds in all groups had continuous access to outdoor range during daylight hours. The daily photoperiod consisted of $16 \mathrm{~h}$ of light and $8 \mathrm{~h}$ of darkness. The lighting intensity was arranged as $3.01 \mathrm{x} \mathrm{m}^{-2}$.

\subsection{Data}

The control and experimental groups were monitored in 8week intervals by the same person to assess the poultry welfare with plumage quality (physical assessment) and pecking behaviour (behavioural assessment) of the birds from 24 to 48 weeks (Sejian et al., 2011). The physical and behavioural assessments in the control and treatment groups were carried out in slatted, litter and range areas. Three observations in each area in each group were made, and each of them was designed in the same way as the other groups.

\subsection{Plumage quality}

A distance scoring system, which is a more animal-friendly, less stressful, and effective and easier way to determine feather damage, was used to assess plumage quality in hens (Bright et al., 2006; Lambton et al., 2013). Three areas of the birds' bodies were scored (neck, back and rump) from 0 (well-feathered body part with no or very little damage) to 4 (severe damage to feathers, several or large naked areas and/or broken skin). Moreover, two areas of flight feathers (tail and wing) were also scored from 0 (intact feathers) to 4 (all feathers missing or broken and/or evidence of bleeding from broken skin). To determine plumage quality, the birds were selected at random for scoring by choosing a hen, counting five hens to the left, and feather-scoring that fifth hen in the slatted, litter and range areas. Ten birds from each area were scored to measure plumage quality. Two birds from each area were caught and examined to assess the vent and cannibalism score. Flock prevalence of feather pecking in control and treatment groups was calculated as a percentage of birds with damaged feathers from the total birds scored.

\subsection{Behavioural observations}

Behaviour observations were recorded with focal animal sampling (Martin and Bateson, 1986) in the afternoon (14:00-16:00) by the same person from a $2 \mathrm{~m}$ distance from the observation area. The observations were carried out on slats, on litter and on range in accordance with a 5 min observation period after a standstill for $2 \mathrm{~min}$ to maintaining a clear 
view of the observation area. The number of bouts/pecks of gentle feather pecking (GFP) were recorded, as well as the number of pecks for severe feather pecking (SFP), tail pecking (TP) and aggressive pecking (AP). Also, the existence of vent pecking (VP) and cannibalistic pecking (CP) as pecking behaviour were measured in this study (Table 1). At the start and end of 5 min observation period, the number of birds in each area was counted and recorded.

\subsection{Analysis}

Total feather score was defined as the sum of the scores for all body parts. Rates of feather pecking behaviour were calculated as pecks or bouts (in the case of GFP) per bird per observation period $(5 \mathrm{~min})$ where average the number of birds before and after observation period (the average rates of feather pecking behaviour : pecks (bouts)/number of birds before and after observation: $5 \mathrm{~min}$ ). All of the data were analysed by means of an ANOVA test procedure which is part of SPSS version 13.00 (SPSS, Inc. 2004). The mean separation was performed using the Duncan test (Snedecor and Cochran, 1989).

\section{Results}

Results from flock prevalence of feather damage and total feather scores of control and treatment groups are presented in Table 2. Based on the study, there were no significant differences for total feather score between control and treatment groups at 24 weeks of age. The total feather score significantly increased with age and varied among the groups at 32, 40 and 48 weeks of age $(P<0.040, P<0.006, P<0.001)$. The final feather score of control group was the worst, with total scores of $0.93(P<0.001)$. The mean proportion of birds affected by any feather damage in control, treatment I and treatment II was respectively $70.00,76.66$ and 70.00 at 24 weeks of age and $100.00,73.30$ and $90.00 \%$ at 48 weeks of age.

The average feather scores for all body regions of the birds in each group are displayed in Table 3 . All differences among the feather score of neck, back, rump, tail and wing at 24, 32, 40 and 48 weeks of age in any group were found to be statistically significant $(P<0.05, P<0.01, P<0.001)$. All differences for same body region calculated at $24,32,40$ and 48 weeks in control group were found to be significantly important as well $(P<0.001)$. Differences for the feather score of neck and rump was found to be significantly important in treatment $\mathrm{I}(P<0.05)$. There were important differences in the feather score of the same body region collected during different periods of the experiment in treatment II, except for the tail region $(P<0.05, P<0.05, P<0.05, P<0.01$, respectively).

The mean rate of pecking behaviour in all groups and the general proportion to type of different pecking behaviour are shown in Table 4. There were no significant differences for the mean rate of pecking behaviour between control and treatment groups. The average number of pecks in the control, treatment I and treatment II were found to be, respectively, $0.183,0.069$ and 0.168 for the first observation period (at 24 weeks of age); 0.155, 0.108 and 0.098 at 32 weeks of age; $0.155,0.046$ and 0.104 at 40 weeks of age; and 0.110 , 0.057 and 0.064 in the final observation period (at 48 weeks of age).

In addition, on the basis of type of feather-pecking activity, significant differences were observed throughout the experiment $(P<0.026, P<0.007, P<0.001$, respectively). The average number of pecks for GFP, SFP, AP and TP were calculated as, respectively, $0.219,0.150,0.112$ and 0.078 at 24 weeks of age; $0.274,0.099,0.015$ and 0.093 at 32 weeks of age; $0.305,0.089,0.012$ and 0.017 at 40 weeks of age; and $0.212,0.054,0.006$ and 0.039 in the final period of experiment. No significant groups of $x$ type of feather pecking interaction were determined for all time periods of this study.

\section{Discussion}

Plumage condition of laying hens is very important for the body of the bird, and it may seriously affect the welfare of bird. Insufficient feather coverage on a hen causes a gradual decreasing production and the economy laying period. Also, the plumage condition might be an input level of the laying hen's welfare. One of the major factors for reducing plumage quality is feather pecking. The causes of and preventative measures for feather pecking and cannibalism are very complicated and multi-factorial elements (Rodenburg et al., 2013). Some of the predisposing factors are overcrowding, excessive light and temperature, insufficient or improperly placed feeders or drinking space, nutritional imbalances including mineral deficiencies, feeding of only pelleted or concentrated feed, feeding high-energy diets heavy in corn or low in fibre, and injuries (Green et al., 2000; Nicol et al., 2003, 2013; Sedlačková et al., 2004; De Haas et al., 2014). Moreover, the high prevalence of these behaviours and feather damage within flocks mainly depends upon whether or not beak trimming is applied (McAdie and Keeling, 2000). An alternative housing system for hens such as free range with an aviary system shows much higher incidences of injurious pecking than in those hens housed in a conventional caged system. Among all production systems, vent pecking is most widespread in free range (Sherwin et al., 2010). Giving birds fermented feed results in a poorer plumage condition than given them dry feed (Engberg et al., 2009). Gilani et al. (2012) found that dark brooding had no detrimental effect on feather pecking on commercial farms.

A more critical factor should be the reduction in the propensity for feather pecking during the rearing phase of layer hens. In this study there were no significant differences for the plumage quality of birds between the groups at 24 weeks of age. This is after the first group had been 
Table 1. Ethogram of behavioural observations*.

\begin{tabular}{ll}
\hline Behaviour & Description \\
\hline Gentle feather pecking & Feather pecking without removal of feathers \\
Severe feather pecking & Feather pecking leading to feather loss \\
Tail pecking & Feather pecking leading to feather loss in tail \\
Aggressive pecking & Forceful downward peck at the head, neck or any part of body \\
Vent pecking & Tissue pecking in vent \\
Cannibalistic pecking & Tissue pecking in any part of body \\
\hline
\end{tabular}

* Savory (1995), Petek and McKinstry (2010)

Table 2. Flock prevalence (FP) ${ }^{1}$ and total feather scores (TFS) ${ }^{2}$ in control and treatment groups.

\begin{tabular}{lccccc}
\hline \multirow{2}{*}{ Groups } & & \multicolumn{4}{c}{ Laying period (weeks) } \\
\cline { 3 - 6 } Control & & 24 & 32 & 40 & 48 \\
\hline \multirow{2}{*}{ Treatment I } & TFS & $0.37 \pm 0.11$ & $0.37 \pm 0.12^{\mathrm{b}}$ & $0.27 \pm 0.14^{\mathrm{a}}$ & $0.93 \pm 0.15^{\mathrm{b}}$ \\
& FP, $\%$ & 70.00 & 73.33 & 73.00 & 100.00 \\
\hline \multirow{2}{*}{ Treatment II } & $0.37 \pm 0.13$ & $0.45 \pm 0.11^{\mathrm{b}}$ & $0.43 \pm 015^{\mathrm{b}}$ & $0.35 \pm 0.12^{\mathrm{a}}$ \\
& FP, $\%$ & 76.66 & 73.00 & 70.00 & 73.30 \\
\hline \multirow{2}{*}{$P$} & TFS & $0.46 \pm 0.14$ & $0.26 \pm 0.12^{\mathrm{a}}$ & $0.25 \pm 0.13^{\mathrm{a}}$ & $0.47 \pm 0.14^{\mathrm{a}}$ \\
& 70.00 & 66.00 & 66.00 & 90.00 \\
\hline 1 The mean proportion of birds within each flock affected by any feather damage. ${ }^{2}$ Mean \pm SE, lower score \\
means better plumage quality; ${ }^{\mathrm{a}-\mathrm{c}}$ within columns; values with different superscript letters differ significantly \\
$(P<0.05, P<0.001)$.
\end{tabular}

outside for a month already. However, the rapid changes in plumage quality were observed in all groups from the beginning onwards. By 32 weeks, all groups developed feather pecking behaviour and the plumage condition declined. Further decreases in plumage condition take place between 32 and 48 weeks. Although the rearing environment may play an important role in the later development of pecking problems, generally the plumage condition is perfect and injurious pecking is minimal when birds are transferred from rearing to laying houses (Blokhuis and Van der Haar, 1992; Huber-Eicher and Wechsler, 1998). All the layers in the control group had feathers that were more or less damaged in the final period of the study, whereas flock prevalence of feather pecking in treatment I and treatment II were 73 and $90 \%$, respectively. In contrast to previous reports (Leenstara et al., 2012), birds having access to range area later resulted in more feather damage. Compare to this study, Gilani et al. (2013) found that percentage of flock with missing feathers was $12 \%$ at 16 weeks and $49 \%$ at 35 weeks.

In this study, the final plumage quality of the birds for all body regions significantly worsened in all groups. Based on the results, more feather damage (greater scores, more damage) was observed to the tail and rump than to other regions of the body in all groups $(P<0.05)$. Also, the best plumage quality of the body in each group was measured for the neck region.

In this study, there were significant differences for the type of feather-pecking activity of laying hens throughout the experiment, except for initial stage of experiment $(P<0.026$, $P<0.007, P<0.001)$. Similar to the findings of Lambton et al. (2013), gentle feather pecking was the most frequently observed behaviour, followed by severe feather pecking, tail pecking and aggressive pecking. It has been reported that gentle feather pecking was observed in 89.2 and $73 \%$ of flocks at 25 and 40 weeks, respectively, in UK free-range and organic farms (Lambton et al., 2010). Farm-level factors examined in Dutch organic farm flocks showed moderate plumage damage in $19 \%$ of flocks and severe damage in $52 \%$ of flocks (Bestman and Wagenaar, 2003). Gentle feather pecking is pecking that results in little or no feather damage and produces no or only a mild response in the recipient layer (McAdie and Keeling, 2000). It is important that gentle feather pecking was rarely correlated with feather damage in any body area (Lambton et al., 2013). Fewer instances of aggressive pecking in this study may be as a result of less feeding competition, because feeding competition may lead to an increase in pecking activity, especially aggressive pecking. On the other hand, cannibalistic behaviour and vent pecking were not observed in our trial. This was prob- 
Table 3. Average feather score for all body regions of the birds in each group.

\begin{tabular}{|c|c|c|c|c|c|c|c|}
\hline Groups & $\begin{array}{l}\text { Laying period } \\
\quad \text { (weeks) }\end{array}$ & Neck & Back & Rump & Tail & Wing & $P$ \\
\hline \multirow[t]{4}{*}{ Control } & 24 & $0.300 \pm 0.10^{\mathrm{Aa}}$ & $0.233 \pm 0.09^{\mathrm{Aa}}$ & $0.400 \pm 0.11^{\mathrm{Aa}}$ & $0.967 \pm 0.13^{\mathrm{Ba}}$ & $0.400 \pm 0.11^{\mathrm{Aa}}$ & 0.001 \\
\hline & 32 & $0.200 \pm 0.11^{\mathrm{Aa}}$ & $0.200 \pm 0.11^{\mathrm{Aa}}$ & $0.367 \pm 0.10^{\mathrm{Aa}}$ & $0.800 \pm 0.12^{\mathrm{Ba}}$ & $0.300 \pm 0.12^{\mathrm{Aa}}$ & 0.001 \\
\hline & 40 & $0.200 \pm 0.11^{\mathrm{Aa}}$ & $0.166 \pm 0.10^{\mathrm{Aa}}$ & $0.400 \pm 0.13^{\mathrm{Aa}}$ & $0.800 \pm 0.13^{\mathrm{Ba}}$ & $0.133 \pm 0.10^{\mathrm{Aa}}$ & 0.001 \\
\hline & 48 & $0.833 \pm 0.10^{\mathrm{Ab}}$ & $0.667 \pm 0.12^{\mathrm{Ab}}$ & $0.833 \pm 0.12^{\mathrm{Ab}}$ & $1.367 \pm 0.13^{\mathrm{Bb}}$ & $0.967 \pm 0.09^{\mathrm{Ab}}$ & 0.05 \\
\hline$P$ & & 0.001 & 0.001 & 0.01 & 0.001 & 0.001 & \\
\hline \multirow[t]{4}{*}{ Treatment I } & 24 & $0.100 \pm 0.11^{\mathrm{Aa}}$ & $0.233 \pm 0.11^{\mathrm{A}}$ & $0.333 \pm 0.13^{\mathrm{Aa}}$ & $1.067 \pm 0.12^{\mathrm{b}}$ & $0.133 \pm 0.11^{\mathrm{A}}$ & 0.001 \\
\hline & 32 & $0.367 \pm 0.12^{\mathrm{Ab}}$ & $0.300 \pm 0.12^{\mathrm{A}}$ & $0.400 \pm 0.11^{\mathrm{Aa}}$ & $0.867 \pm 0.11^{\mathrm{b}}$ & $0.300 \pm 0.10^{\mathrm{A}}$ & 0.01 \\
\hline & 40 & $0.100 \pm 0.13^{\mathrm{Aa}}$ & $0.300 \pm 0.11^{\mathrm{A}}$ & $0.600 \pm 0.12^{\mathrm{Bb}}$ & $0.800 \pm 0.11^{\mathrm{b}}$ & $0.333 \pm 0.11^{\mathrm{A}}$ & 0.05 \\
\hline & 48 & $0.067 \pm 0.11^{\mathrm{Aa}}$ & $0.167 \pm 0.10^{\mathrm{A}}$ & $0.300 \pm 0.11^{\mathrm{Ba}}$ & $0.967 \pm 0.12^{\mathrm{C}}$ & $0.267 \pm 0.11^{\mathrm{B}}$ & 0.001 \\
\hline$P$ & & 0.05 & ns & 0.05 & ns & ns & \\
\hline \multirow[t]{4}{*}{ Treatment II } & 24 & $0.133 \pm 0.12^{\mathrm{Aa}}$ & $0.166 \pm 0.12^{\mathrm{Ab}}$ & $0.300 \pm 0.10^{\mathrm{Aa}}$ & $0.933 \pm 0.11^{\mathrm{b}}$ & $0.333 \pm 0.12^{\mathrm{Ac}}$ & 0.001 \\
\hline & 32 & $0.100 \pm 0.11^{\mathrm{Aa}}$ & $0.067 \pm 0.11^{\mathrm{Aa}}$ & $0.233 \pm 0.10^{\mathrm{Aa}}$ & $0.833 \pm 0.10^{\mathrm{B}}$ & $0.067 \pm 0.11^{\mathrm{Aa}}$ & 0.001 \\
\hline & 40 & $0.100 \pm 0.12^{\mathrm{Aa}}$ & $0.033 \pm 0.10^{\mathrm{Aa}}$ & $0.433 \pm 0.12^{\mathrm{Bb}}$ & $0.700 \pm 0.09^{\mathrm{C}}$ & $0.067 \pm 0.10^{\mathrm{Aa}}$ & 0.001 \\
\hline & 48 & $0.267 \pm 0.09^{\mathrm{Ab}}$ & $0.367 \pm 0.12^{\mathrm{Ac}}$ & $0.600 \pm 0.11^{\mathrm{Bb}}$ & $0.933 \pm 0.10^{\mathrm{C}}$ & $0.200 \pm 0.11^{\mathrm{Ab}}$ & 0.001 \\
\hline$P$ & & 0.05 & 0.05 & 0.05 & ns & 0.01 & \\
\hline
\end{tabular}

a-c Within columns, values with different superscript letters differ significantly $(P<0.05, P<0.001)$; ns: not significant.

$\mathrm{A}-\mathrm{B}$ Within rows, values with different superscript letters differ significantly $(P<0.05, P<0.01, P<0.001)$.

Table 4. The mean rate of pecking behaviour in the groups and mean proportion of different pecking behaviour (number/5 min).

\begin{tabular}{lcccc}
\hline Groups & $24 \mathrm{w}$ & $32 \mathrm{w}$ & $40 \mathrm{w}$ & $48 \mathrm{w}$ \\
\hline Control & 0.183 & 0.155 & 0.155 & 0.111 \\
Treatment I & 0.069 & 0.108 & 0.046 & 0.057 \\
Treatment II & 0.168 & 0.098 & 0.104 & 0.064 \\
\hline Type of feather peck & & & & \\
\hline GFP & 0.219 & $0.274^{\mathrm{a}}$ & $0.305^{\mathrm{a}}$ & $0.212^{\mathrm{a}}$ \\
SFP & 0.150 & $0.099^{\mathrm{b}}$ & $0.089^{\mathrm{b}}$ & $0.054^{\mathrm{b}}$ \\
AP & 0.112 & $0.015^{\mathrm{c}}$ & $0.012^{\mathrm{c}}$ & $0.006^{\mathrm{c}}$ \\
TP & 0.078 & $0.093^{\mathrm{b}}$ & $0.017^{\mathrm{b}}$ & $0.039^{\mathrm{b}}$ \\
\hline ANOVA & & & & \\
\hline Groups & 0.227 & 0.692 & 0.381 & 0.321 \\
Type of feather peck & 0.351 & 0.026 & 0.007 & 0.001 \\
Interaction between groups & 0.323 & 0.950 & 0.895 & 0.699 \\
$\times$ type of feather pecking & & & & \\
\hline
\end{tabular}

$\overline{\text { GFP: gentle feather pecking; SFP: severe feather pecking; AP: aggressive pecking; TP }}$ tail pecking

ably due to the genetic strain of bird and the fact that they were kept in more spread-out groups (Petek and McKinstry, 2010). Most forms of feather-pecking activity increase in both prevalence and rate with age. Previous studies have similarly noted increased feather pecking with bird age (Nicol et al., 2003; Gilani et al., 2013), especially at higher stocking densities (Zimmerman et al., 2006) and if flocks were fed on pelleted feed (Lambton et al., 2010). In the current study, the rate for all types of pecking behaviour decreased with age, as previously reported by Chow and Hogan (2005). Shimmura et al. (2008) reported that most free-range hens spent their time outside foraging and that the proportion of feather pecking decreased in free-range layer chickens during their access to range, and a similar tendency was observed also in aggressive pecking.

The results of this study clearly showed that increasing use of range is important to reduce pecking behaviour since the more frequent total pecking behaviour and more feather damage were observed in the control group compared to the experimental groups. As reported previously, greatest range use is achieved by allowing the hens range usage as early as possible (Anonymous, 2011).

In conclusion, injurious feather pecking and cannibalism may have a serious effect on poultry welfare. When searching for an on-farm solution to reduce this harmful behaviour, it is important to identify the potential risk factors involved in the development of feather pecking on every flock. Integrated application of an appropriate husbandry management program and multidisciplinary research might be very useful in reducing the levels of feather pecking. The decision about the time until first access to range is a husbandry practice, and access to range area as early as possible at the beginning of the laying period may be a useful tool to reduce negative effects of injurious pecking in free-range layer chickens, with beneficial effects on both welfare and productivity. However, even with these measures, feather pecking and cannibalism will remain a significant problem. 
Acknowledgements. This study was supported with a grant from the Scientific Research Project Directorship of Uludag University (project no: UAP(V)-2011/56).

Edited by: K. Wimmers

Reviewed by: two anonymous referees

\section{References}

Anonymous: The Bristol Pecking Project, Newsletter II, University of Bristol, Bristol, UK, 2011.

Anonymous: Netherlands bans beak trimming in layer hens from 2018, World Poultry, 12 June, http://www.worldpoultry.net/Layers/Health/2013/6/Netherlandsbans-beak-trimming-in-layer-hens-from-2018-1281266W/ (last access: 4 February 2015), 2013.

Bestman, M. W. P. and Wagenaar, J. P.: Farm level factors associated with feather pecking in organic laying hens, Livest. Prod. Sci., 80, 133-140, 2003.

Blokhuis, H. J. and Van der Haar, J. W.: Effects of pecking incentives during rearing on feather pecking of laying hens, Br. Poult. Sci., 33, 17-24, 1992.

Bright, A., Jones, T. A., and Dawkins, M. S.: A non-intrusive method of assessing plumage condition in commercial flocks of laying hens, Anim. Welfare, 15, 113-118, 2006.

Brunberg, E., Jensen, P., Isaksson, A., and Keeling, L.: Feather pecking behavior in laying hens: Hypothalamic gene expression in birds performing and receving pecks, Poult. Sci., 90, 11451152, 2011.

Chow, A. and Hogan, J. A.: The development of feather pecking in Burmese red junglefowl: the influence of early experience with exploratory-rich environments, Appl. Anim. Behav. Sci., 93, 283-294, 2005.

De Haas, E. N., Bolhuis, J. E., de Jong, I. C., Kemp, B., Janczak, A. M., and Rodenburg, T. B.: Predicting feather damage in laying hens during the laying period. Is it the past or is it the present?, Appl. Anim. Behav. Sci., 160, 75-85, 2014.

Engberg, R. M., Hammershoj, M., Johansen, N. F., Abousekken, M. S., Steenfeldt, S., and Jensen, B. B.: Fermented feed for laying hens: effects on egg production, egg quality, plumage condition and composition and activity of intestinal microflora, Br. Poult. Sci., 50, 228-239, 2009.

Gilani, A. M., Knowles, T. G., and Nicol, C. J.: The effect of dark brooders on feather pecking on commercial farms, Appl. Anim. Behav. Sci., 142, 42-50, 2012.

Gilani, A. M., Knowles, T. G., and Nicol, C. J.: The effect of rearing environment on feather pecking in young and adult laying hens, Appl. Anim. Behav. Sci., 148, 54-63, 2013.

Gilani, A. M., Knowles, T. G., and Nicol, C. J.: Factors affecting ranging behaviour in young and adult laying hens, Br. Poult. Sci., $55,127-135,2014$.

Green, L. E., Lewis, K., Kimpton, A., and Nicol, C. J.: Crosssectional study of the prevalence of feather pecking in laying hens in alternative systems and its associations with management and disease, Vet. Rec., 147, 233-238, 2000.

Huber-Eicher, B. and Wechsler, B.: The effect of quality and availability of foraging materials on feather pecking in laying hen chicks, Anim. Behav., 55, 861-873, 1998.
Lambton, S. L., Knowles, T. G., Yorke, C., and Nicol, C. J.: The risk factors affecting the development of gentle and severe feather pecking in loose housed laying hens, Appl. Anim. Behav. Sci., 123, 32-42, 2010.

Lambton, S. L., Nicol, C. J., Friel, M., Main, D. C., McKinstry, J. L., Sherwin, C. M., Walton, J., and Weeks, C. A.: A bespoke management package can reduce levels of injurious pecking in loose-housed laying hen flocks, Vet. Rec., 172, 423-428, 2013.

Leenstra, F., Maurer, V., Bestman, M., van Sambeek, F., Zeltner, E., Reuvekamp, B., Galea, F., and van Niekerk, T.: Performance of commercial laying hen genotypes on free range and organic farms in Switzerland, France and The Netherlands, Br. Poult. Sci., 53, 282-290, 2012.

Martin, P. and Bateson, P.: Measuring behaviour: an introductory guide, Cambridge University Press, Cambridge et al., UK, 1986.

Mahboub, H. D., Müller, J., and von Borell, E.: Outdoor use, tonic immobility, heterophil/lymphocyte ratio and feather condition in free-range laying hens of different genotype, Br. Poult. Sci., 45, 738-744, 2004.

McAddie, T. M. and Keeling, L. J.: Effect of manipulating feathers of laying hens on the incidence of feather pecking and cannibalism, Appl. Anim. Behav. Sci., 68, 215-229, 2000.

Morris, H. J.: Environmental management of injurious pecking in turkeys, $\mathrm{PhD}$ thesis, Faculty of Medicine and Veterinary Science, Bristol University, Bristol, UK, 2007.

Nicol, C. J., Pötzsch, C., Lewis, K., and Green, L. E.: Matched concurrent case-control study of risk factors for feather pecking in hens on free-range commercial farms in the UK, Br. Poult. Sci., 44, 515-523, 2003.

Nicol, C. J., Bestman, M., Gilani, A. M., De Haas, E. N., De Jong, I. C., Lambton, S., Wagenaar, J. P., Weeks, C. A., and Rodenburg, T. B.: The prevention and control of feather pecking: application to commercial systems, Worlds Poult. Sci. J., 69, 775-788, 2013.

NRC: Nutrient requirements of poultry. 9th rev. ed., National Research Council, Washington D.C., USA, 1994.

Petek, M.: Can early access to the range area be a solution to reduce injurious pecking in layer chickens? Science in the Service of Animal Welfare: Priorities around the World UFAW International Animal Welfare Science Symposium, Universitat Autònoma de Barcelona, Barcelona, Spain, 4-5 July 2013.

Petek, M. and McKinstry, J. L.: Reducing the Prevalence and Severity of Injurious Pecking in Laying Hens without Beak Trimming, Uludag. Univ. J. Fac. Vet. Med., 29, 61-68, 2010.

Picket, H.: Controlling feather pecking \& cannibalism in laying hens without beak trimming. A Compassion in World Farming Report, October 2009, Registered Charity No. 1095050, http://www.ciwf.org.uk/includes/documents/cm_docs/2009/c/ controlling_feather_pecking_and_cannibalism_without_beak_ trimming.pdf (last access: 4 February 2015), 2009.

Rodenburg, T. B., Van Krimpen, M. M., De Jong, I. C., De Haas, E. N., Kops, M. S., Riedstra, B. J., Nordquist, R. E., Wagenaar, J. P., Bestman, M., and Nicol, C. J.: The prevention and control of feather pecking in laying hens: identifying the underlying principles, Worlds Poult. Sci. J., 69, 361-374, 2013.

Savory, C. J.: Feather pecking and cannibalism, Worlds Poult. Sci. J., 51, 215-219, 1995.

Sedlačková, M., Bilčík, B., and Koštál, L.: Feather Pecking in Laying Hens: Environmental and Endogenous Factors, Acta Vet Brno, 73, 521-531, 2004. 
Sejian, V., Lakritz, J., Ezeji, T., and Lal, R.: Assessment methods and indicators of animal welfare, Asian J. Anim. Vet. Adv., 6, 301-315, 2011.

Sherwin, C. M., Richards, G. J., and Nicol, C. J.: Comparison of the welfare of layer hens in 4 housing systems in UK, Br. Poult. Sci., 51, 488-499, 2010.

Sherwin, C. M., Nasr, M. A. F., Gale, E., Petek, M., Stafford, K., Turp, M., and Coles, G. C.: Prevalence of nematode infection and faecal egg counts in free-range laying hens: relations to housing and husbandry, Br. Poult. Sci., 54, 12-23, 2013.

Shimmura, T., Suzuki, T., Hirahara, S., Eguchi, Y., Uetake, K., and Tanaka, T.: Pecking behaviour of laying hens in single-tiered aviaries with and without outdoor area, Br. Poult. Sci., 49, 396401, 2008

Snedecor, G. W. and Cochran, W. G.: Statistical Methods. 8th ed., Iowa State University, Ames, IA, USA, 1989.

SPSS: SPSS 13.00 Computer Software, SPSS, Inc., Chicago, IL, USA, 2004.

Tauson, R., Kjaer, J., Maria, G. A., Cepero, R., and Holm, K. E.: Applied scoring of integument and health in laying hens, http://www.laywel.eu/web/pdf/deliverables31-33health.pdf (last access: 4 February 2015), 2005.
Weeks, C. A., Friel, M., Lambton, S. L., Main, D. C. J., McKinstry, J. L., Petek, M., Sherwin, C. M., Thierstein, J., Walton, J., and Nicol, C. J.: Uptake of different types of intervention aimed at reducing injurious pecking on commercial free-range laying hen farms in the UK, in: Proceedings of the 30th Poultry Science Symposium. Alternative Systems for Poultry - Health, Welfare and Productivity, 7-9 September 2011, University of Strathclyde, Glasgow, UK, http://www.cabi.org/ uploads/animal-science/worlds-poultry-science-association/ WPSA-glasgow-scotland-2011/49_Weeks_2_poster.pdf (last access: 4 February 2015), 2011.

Zimmerman, P. H., Lindberg, A. C., Pope, S. J., Glen, E., Bolhuis, J. E., and Nicol, C. J.: The effect of stocking density, flock size and modified management on laying hen behaviour and welfare in a non-cage system, Appl. Anim. Behav. Sci., 101, 111-124, 2006. 